\title{
Timely antenatal diagnosis of malformations - Still a far cry
}

\author{
Raina Chawla, Priya K. Ballal, Pralhad Kushtagi \\ Department of Obstetrics-Gynecology, Kasturba Medical College, Constituent of Manipal University, MANGALORE, India \\ Correspondence: Pralhad Kushtagi. Address: A-15, KMC Staff Quarters, Light House Hill Road, MANGALORE 575003, \\ India. Telephone: 91-824-241-1985. Fax: 91-824-242-8183. Email: pralhadkushtagi@hotmail.com.
}

Received: May 23, 2012

DOI : $10.5430 / j b g c . v 2 n 2 p 64$

Accepted: August 15, 2012

Published: December 1, 2012

\section{Abstract}

Background: Some countries where termination of pregnancy is legalized, it is permitted only up to 20 weeks of gestation. Fetal anomaly detection scan (FADS) is usually advised between 18-20 weeks of pregnancy. Despite timely advice most women turn up late and this fails to provide enough time to terminate pregnancy within the law in the event of a severe anomaly.

Objective: To determine the incidence of congenital malformations, and to study the extent of utilisation of ultrsonography for antenatal diagnosis.

Methods: The records of patients (April 2010 - May 2012) who delivered a baby with a congenital malformation, those having undergone termination of pregnancy for malformed fetus and the cases with malformations diagnosed on neonatal autopsy were reviewed. Data was collected in a structured format that included patient characteristics (age, parity, religion, and maternal risk factors), details of antenatal care (period of first visit, prenatal ultrasound for fetal anatomy) and anomalies (ultrasound detection, after termination/ birth).

Results: During the period of review there were 12238 pregnancy records (11675 deliveries after 28 weeks, and 563 expulsions of pregnancies before 28 weeks; excluding ectopic and molar pregnancies) and 121 congenital malformations giving the incidence of malformations as 1.04 per 100 deliveries; and 0.99 per 100 total pregnancy outcomes. The average age of women was $26.6 \pm 4.2$ years with $5.8 \%$ being beyond 35 years of age. The majority of women were multiparous. Only $26.4 \%$ had FADS prior to 20 weeks. Sonogram performed anytime during the pregnancy could detect $55.9 \%$ (62 of 121)) of congenital malformations suggesting that it was missed in $44.1 \%$ cases. Those who submitted for FADS between $14-24$ weeks of pregnancy, the malformations were detected in $53.2 \%$ of 66 pregnancies. The majority (45.2\%) of anomalies diagnosed by ultrasonography were neural tube defects.

Conclusion: Overall detection of malformations is low indicating necessity for specific guidelines for performing FADS.

\section{Key words}

Fetal anomaly detection scan, Missed diagnosis, Termination of pregnancy

\section{Introduction}

Congenital malformations that have cosmetic or functional significance are seen in nearly $3 \%$ of deliveries ${ }^{[1]}$. The incidence of severe structural congenital malformations varied from $1.99 \%$ to $9.12 \%$ in different European registries ${ }^{[2]}$. 
The overall incidence of congenital malformations over a 5 year period in the Northern part of India was found to be $1.78 \%{ }^{[3]}$. Most of these can be detected by ultrasonography during antenatal scan. Screening for fetal anomalies is routine and efforts are being made to standardize it in several developing countries ${ }^{[4]}$. In India, targeted screening for fetal anomalies is recommended to be carried out routinely between $18-20$ weeks of gestation ${ }^{[5]}$.

The other important issue pertains to the legality of performing termination of pregnancy for fetal anomalies and the law varies widely in this respect in different countries ${ }^{[6]}$. For example, in the United Kingdom ${ }^{[7]}$ terminations for fetal abnormality are allowed without any gestational age limit. In stark contrast, countries like Malawi ${ }^{[8]}$ have strict abortion laws which allow abortion only for preservation of a woman's life, only after the opinion of two independent obstetricians and with spousal consent. Similarly, several middle-east countries also have extremely restrictive abortion laws permitting them only if the woman's life is in danger ${ }^{[9]}$. In India, The Medical Termination of Pregnancy (MTP) Act offers abortion services only up to 20 weeks of pregnancy ${ }^{[10]}$. Timely diagnosis of anomalies prior to 20 weeks would thus enable the physician to offer the option of termination of pregnancy in the event of a severe anomaly in a country like India. The delay of even one week in carrying out the advice for antenatal scan and more so in the event of one harbouring severe anomaly would fail to provide enough time to act within the law.

The present descriptive study was designed to find out the period of gestation when fetal anomaly detection scan (FADS) is done, and determine the incidence of anomalies in a District Government Maternity Hospital.

\section{Patients and methods}

The review was carried out at a District Government Maternity Hospital attached to a Medical College attending to patients directly and to referrals from neighbouring districts of South India on the west coast. The hospital is a major obstetric unit in the region, mainly catering to low risk obstetric needs. Nearly $60 \%$ of ultrasound examinations are done at different sonographic clinics decided by the couple.

The data of cases from April 2010 through May 2012 was collected from the birth defect registry. Records of reported anomalies and patient information are maintained in the registry. Details of women who (a) delivered a baby with a congenital malformations, (b) had termination of pregnancy for a congenitally malformed fetus and (c) malformations diagnosed on autopsy were reviewed from this registry. The concerned case records were retrieved and the reports of autopsy/ chromosomal analysis were reviewed wherever available.

Data was collected in a structured format designed for the study. It included patient characteristics (Age, parity, religion and maternal risk factors), details of antenatal care (period of first visit, prenatal ultrasound for fetal anatomy) and anomalies (ultrasound detection, after termination/ birth). Maternal risk factors included were positive history in family and self for congenital malformations, consanguinity, diabetes mellitus, multiple gestation, erythematous fever and exposure to known teratogens in pregnancy.

The date of suggestion for FADS and the date of reporting were specifically looked for in the case records. The detailed description of fetal anatomy in the ultrasound report, details of recorded anomalies in the newborn and available corroborative reports were noted. The ultrasound examination was performed by different sonologists in different facilities and they were not involved with clinical management of the case.

Information about the number of deliveries and the pregnancy terminations/ abortions during the period of study was obtained from the labor room register. The ectopic and molar pregnancies were excluded from the compilation. Malformations were grouped according to the anatomical system involved.

The descriptive analysis to know the incidence of malformations, proportion of women seeking sonographic investigation (using a reference point of 20 weeks) and accuracy of ultrasonography to detect malformations was carried out. 
Significance of difference between proportions and averages was determined using chi square and student's t-tests respectively.

\section{Results}

There were a total of 11675 deliveries after 28 weeks of gestation and 563 abortions ( $<28$ weeks) during the study period. The total number of congenital malformations in this period was 121 . The incidence of malformations was 1.04 per 100 deliveries. When abortions were also included, the incidence of malformations was 0.99 per 100 pregnancy outcomes.

The average age of mothers who had given birth to malformed offspring was $26.6 \pm 4.2$ years. There were an almost equal number of parous (61 of 121, 50.4\%) and nulliparous (60 of 121, 49.6\%) women. The average age of women without fetal malformations delivering at the same centre during the study period was $26.3 \pm 4.1$ years, and this was not significantly different $(p=1)$ than that of women with malformed offspring. The number of elderly ( $>35$ years of age) women having fetal malformations was 9 of $121(7.4 \%)$. The incidence of fetal malformations among 553 women beyond 35 years in the population studied was slightly higher $(1.2 \%)$ than the overall incidence $(1 \%)$ and this was not statistically significant $(p=$ 1) (see Table 1).

Table 1. Distribution of cases with fetal malformation according to age

\begin{tabular}{lllll}
\hline & $\begin{array}{l}\text { Pregnancy with fetal } \\
\text { malformation } \\
(\mathbf{N}=121)\end{array}$ & $\begin{array}{l}\text { Pregnancy without } \\
\text { malformation } \\
(\mathbf{N = 1 1 5 5 4})\end{array}$ & Significance \\
\hline Mean Age (years \pm SD) & $26.6 \pm 4.2$ & $26.3 \pm 4.1$ & $p=1$ \\
Age groups & $\leq 19(\mathrm{n}=338)$ & $1(0.2)$ & $337(99.6)$ & \\
$($ year, \%) & $20-34(\mathrm{n}=11784))$ & $111(1.1)$ & $10673(98.9)$ & $p=0.15$ \\
& $\geq 35(\mathrm{n}=553)$ & $9(7.4)$ & $544(4.7)$ & \\
\hline
\end{tabular}

Note. $\mathrm{SD}=1$ Standard Deviation

Poor obstetric performance in the past was present in 23.9\% (29 of 121) of pregnancies carrying malformed fetus. An apparent increase in recording anomalies was noted as the parity increased if the woman had previous miscarriage. Number of cases with previous stillbirth was too small to form any opinion (see Table 2).

Table 2. Obstetric history of women with malformed fetuses/ neonates $(\mathrm{N}=121)$

\begin{tabular}{|c|c|c|c|c|c|}
\hline \multirow{2}{*}{ Parity } & \multirow{2}{*}{ Cases $(\%)$} & \multicolumn{2}{|c|}{ Previous Abortion(s) } & \multicolumn{2}{|c|}{ Previous Stillbirth(s) } \\
\hline & & 1 & $\geq 2$ & 1 & $\geq 2$ \\
\hline 0 & $60(49.6)$ & $7(11.7)$ & $6(10)$ & - & - \\
\hline 1 & $42(34.7)$ & $6(14.3)$ & $1(2.3)$ & $4(9.5)$ & - \\
\hline 2 & $11(9.1)$ & $2(18.2)$ & $1(9.1)$ & - & $1(9.1)$ \\
\hline 3 & $5(4.1)$ & - & - & $1(20)$ & - \\
\hline$\geq 4$ & $3(2.5)$ & - & - & - & - \\
\hline Total & 121 & 15 (12.4) & $8(6.6)$ & $5(4.1)$ & $1(0.8)$ \\
\hline
\end{tabular}

No contributory history was evident in majority of the affected pregnancies (93 cases, 76.9\%). Among those affected pregnancies positive for some of the risk factors, history of consanguineous marriage (42.9\%) and presence of multiple pregnancies $(28.6 \%)$ were more common. There were 8 twin pregnancies $(6.6 \%)$ with congenital malformations in one or both twins (see Table 3). 
Table 3. Maternal Risk Factors in women with malformed fetuses/ neonates

\begin{tabular}{|c|c|c|}
\hline Maternal Risk Factor & Cases & $\%$ \\
\hline No obvious history & 93 & 76.9 \\
\hline Positive history & 28 & 23.1 \\
\hline Previous anomalous fetus & 4 & 14.3 \\
\hline Twin pregnancy & 8 & \multirow{4}{*}{28.6} \\
\hline - Monochorionic Diamniotic & (6) & \\
\hline - Dichorionic Diamniotic & (1) & \\
\hline - Conjoint twins & (1) & \\
\hline Maternal congenital heart disease & 1 & 3.7 \\
\hline Teratogenic drug exposure in the $1^{\text {st }}$ trimester (Anti epileptics) & 2 & 7.1 \\
\hline Overt Diabetes & 1 & 3.7 \\
\hline Consanguinity & 12 & 42.9 \\
\hline
\end{tabular}

Most of the 121 mothers having an affected pregnancy had their first antenatal visit before 20 weeks (101 cases, $83.5 \%$ ). In 4 women, details of the first visit were not available. Only 32 of these $101(31.6 \%)$ had a documented FADS done prior to 20 weeks. Nearly a third (38 cases, $31.4 \%$ ) of patients did not have an ultrasound performed prior to 28 weeks. Amongst these, 32 patients had an ultrasound done only in the 3rd trimester and 6 women did not have an ultrasound performed at any time in their pregnancy. The details of the exact period of gestation of the anomaly scan for 4 patients were not clearly recorded (see Table 4).

Table 4. Relationship of period of gestation with 1st antenatal visit and FADS $(\mathrm{N}=121)$

\begin{tabular}{|c|c|c|c|c|c|c|c|}
\hline \multirow[b]{2}{*}{ Gestation in weeks } & \multicolumn{2}{|c|}{ Cases } & \multicolumn{3}{|c|}{$1^{\text {st }}$ antenatal visit } & \multicolumn{2}{|c|}{ Anomaly detection } \\
\hline & n & $\%$ & $\leq 20$ weeks & $>20$ weeks & $\begin{array}{l}\text { Details } \\
\text { not } \\
\text { available }\end{array}$ & $\begin{array}{l}\text { Ultrasound } \\
\text { N (\%) }\end{array}$ & $\begin{array}{l}\text { Physical } \\
\text { examination/ } \\
\text { autopsy/ others* } \\
\text { N (\%) }\end{array}$ \\
\hline FADS & 111 & 91.7 & & & & $62(55.9)$ & $49(44.1)$ \\
\hline - $\quad 14-20$ & 32 & 26.4 & 32 & NA & 0 & $17(53.1)$ & $15(46.9)$ \\
\hline - $\quad 20 \mathrm{w} 1 \mathrm{~d}-24$ & 34 & 28.1 & 32 & 2 & 0 & $16(47)$ & $18(53)$ \\
\hline - $\quad 24 \mathrm{w} 1 \mathrm{~d}-28$ & 13 & 10.7 & 12 & 1 & 0 & $10(77)$ & $3(23)$ \\
\hline - $\quad$ After 28w1d & 32 & 26.4 & 22 & 10 & 0 & $19(59.4)$ & $13(40.6)$ \\
\hline $\begin{array}{l}\text { Ultrasound not done at } \\
\text { any time }\end{array}$ & 6 & 5 & 3 & 3 & 0 & - & 6 \\
\hline Details not available & 4 & 3.3 & NA & NA & 4 & - & 4 \\
\hline Total & 121 & & 101 & 16 & 4 & $62(51.2)$ & $59(48.8)$ \\
\hline
\end{tabular}

* Cases in whom FADS did not detect anomaly; $\mathrm{w}=$ week, $\mathrm{d}=$ day, $\mathrm{NA}=$ Not available

The overall detection rate of fetal malformations at sonographic evaluation performed anytime during their pregnancy was only $55.9 \%$ (62 of 111 patients). In those who had their evaluation prior to 20 weeks of pregnancy it was $53.1 \%$ (17 of 32 FADS). Anytime the screening was carried out, the effort helped to discover more cases with malformations. It is a matter of concern that in $44.1 \%$ cases, the malformation was not picked up on ultrasonographic evaluation.

The point of interest to note was that only 16 of the 101 women (15.8\%) had their first antenatal visit (prior to 20 weeks) at the treated hospital. Fifteen of these 16 women $(93.75 \%$ ) were advised a FADS between $14-20$ weeks pregnancy. Ten of these 15 (66.7\%) followed this advice and the anomaly detection rate in them was $60 \%$ (6 of 10 cases). The anomaly was missed in 4 cases and these were detected after birth. They included 2 cases of cleft lip and palate, an acyanotic heart 
disease and a lumbar meningocele. The case that was not advised a FADS prior to 20 weeks had her second visit at 23 weeks of pregnancy after her initial visit in the first trimester.

About half of the cases of anomalies $(48.8 \%, 59$ of 121$)$ were diagnosed following birth, either by clinical examination, investigations (ultrasound, echocardiogram) or on autopsy. Eighty three per cent of these (49 cases) were missed during their antenatal scan.

The overall detection rate for anomalies was $50 \%$ when the ultrasound was done between $14-24$ weeks. The rate of detection for different anomalies by ultrasound was $77.8 \%$ (28 out of 36 ) for neural tube defects (highest), 21.4\% ( 3 out of 14) for facial defects, 33.3\% (4out of 12) for cardiac malformations, $25 \%$ ( 3 out of 12 ) for limb defects and $48.7 \%$ ( 7 out of 15) for multiple anomalies.

The profile of anomalies detected on ultrasonographic evaluation and the gestational age when they were diagnosed is given in Table 5. The majority were neural tube defects (45.2\%). Higher proportion of cases with malformations (45 of 62 cases, $72.6 \%$ vs. 17 of 62 cases, $27.4 \%$ after and up to 20 weeks respectively; $p=0.16$ ) were diagnosed after 20 weeks of pregnancy. Nearly $93.3 \%$ of 45 cases diagnosed later than 20 weeks had their earlier antenatal visit in the $1^{\text {st }}$ trimester but only $3(6.7 \%$ of 45 cases $)$ had a FADS done prior to 20 weeks.

Table 5. Profile of anomalies diagnosed on FADS and the gestational age at diagnosis

\begin{tabular}{|c|c|c|c|c|c|c|c|c|}
\hline \multirow{3}{*}{ Anomaly } & \multicolumn{7}{|c|}{ Gestation in weeks at diagnosis } & \multirow{3}{*}{ Total N (\%) } \\
\hline & \multicolumn{2}{|c|}{$\leq 20$ weeks } & \multicolumn{2}{|c|}{$>20$ weeks } & \multirow[t]{2}{*}{$\begin{array}{l}20^{+}-24 \\
(\mathrm{~N})\end{array}$} & \multirow[t]{2}{*}{$\begin{array}{l}24^{+}-28 \\
(\mathrm{~N})\end{array}$} & \multirow[t]{2}{*}{$\begin{array}{l}>\mathbf{2 8} \\
(\mathrm{N})\end{array}$} & \\
\hline & $\mathbf{N}$ & $\%$ & $\mathbf{N}$ & $\%$ & & & & \\
\hline $\begin{array}{l}\text { Neural tube defects, } \\
\text { intracranial anatomical } \\
\text { malformations }\end{array}$ & 10 & 35.7 & 18 & 64.3 & 7 & 4 & 7 & $28(45.2)$ \\
\hline Cardiac Malformations & 1 & 25 & 3 & 75 & - & - & 3 & $4(6.5)$ \\
\hline Renal Malformations & 2 & 28.6 & 5 & 83.3 & 1 & 2 & 2 & $7(11.3)$ \\
\hline Facial defects & 1 & 33.3 & 2 & 66.7 & 1 & - & 1 & $3(4.8)$ \\
\hline Limb Deformities & 0 & 0 & 3 & 100 & 2 & - & 1 & $3(4.8)$ \\
\hline $\begin{array}{l}\text { Congenital diaphragmatic } \\
\text { hernia }\end{array}$ & 0 & 0 & 6 & 100 & 2 & 3 & 1 & $6(9.7)$ \\
\hline $\begin{array}{l}\text { Cystic Adenomatoid } \\
\text { Malformation of the lung }\end{array}$ & 0 & 0 & 1 & 100 & - & - & 1 & $1(1.6)$ \\
\hline Hydrops & 2 & 66.7 & 1 & 33.3 & - & - & 1 & $3(4.8)$ \\
\hline Multiple anomalies & 1 & 14.3 & 6 & 83.3 & 3 & 1 & 2 & $7(11.3)$ \\
\hline Total & 17 & 27.4 & 45 & 72.6 & $16(25.8)$ & $10(15.8)$ & $19(30.2)$ & 62 \\
\hline
\end{tabular}

Out of the 17 pregnancies in which the anomaly was detected before 20 weeks by ultrasound, all (94.1) except a case of cleft lip/ palate underwent medical termination of pregnancy.

Despite having had ultrasonographic examination, 49 anomalies (44.1\%) were not diagnosed antenatally. The anomalies missed by ultrasound are shown in Table 6 .

Of the anomalies missed on FADS, only 15 women (30.6\%) had the ultrasound performed prior to 20 weeks. Pregnancies with missed anomalies (26.5\%) had the detection made only in the 3rd trimester with no earlier documented scans and the majority (49.2\%) had the FADS done between 20 weeks 1 day and 28 weeks. 
Table 6. Profile of anomalies missed on FADS (49)

\begin{tabular}{|c|c|c|c|c|c|c|c|c|}
\hline \multirow{3}{*}{ Anomaly } & \multicolumn{7}{|c|}{ Gestation in weeks at diagnosis } & \multirow{3}{*}{ Total N (\%) } \\
\hline & \multicolumn{2}{|c|}{$\leq 20$ weeks } & \multicolumn{2}{|c|}{$>20$ weeks } & \multirow{2}{*}{$\begin{array}{l}20^{+}-24 \\
(\mathrm{~N})\end{array}$} & \multirow{2}{*}{$\begin{array}{l}24^{+}-28 \\
\text { (N) }\end{array}$} & \multirow{2}{*}{$\begin{array}{l}>28 \\
(\mathbf{N})\end{array}$} & \\
\hline & $\mathbf{N}$ & $\%$ & $\mathbf{N}$ & $\%$ & & & & \\
\hline $\begin{array}{l}\text { Neural tube defects, intracranial } \\
\text { anatomical malformations }\end{array}$ & 3 & 37.8 & 5 & 62.5 & 2 & 1 & 2 & $8(16.3)$ \\
\hline Cardiac Malformations & 3 & 37.8 & 5 & 62.5 & 5 & - & - & $8(16.3)$ \\
\hline Facial defects & 5 & 45.4 & 6 & 54.5 & 4 & 1 & 1 & $11(22)$ \\
\hline Limb Deformities & 3 & 33.3 & 6 & 66.7 & 3 & - & 3 & $9(18.4)$ \\
\hline Multiple anomalies & 1 & 12.5 & 7 & 87.5 & 2 & 1 & 4 & $8(16.3)$ \\
\hline Ambiguous genitalia & - & - & 1 & 100 & - & - & 1 & $1(2)$ \\
\hline Gastroschisis & - & - & 1 & 100 & - & - & 1 & $1(2)$ \\
\hline Imperforate anus & - & - & 1 & 100 & 1 & - & - & $1(2)$ \\
\hline Hypospadias & - & - & 1 & 100 & 1 & - & - & $1(2)$ \\
\hline Cystic Hygroma & - & - & 1 & 100 & - & - & 1 & $1(2)$ \\
\hline Total & 15 & 30.6 & 34 & 69.4 & $18(36.7)$ & $3(61.2)$ & $13(26.5)$ & 49 \\
\hline
\end{tabular}

\section{Discussion}

The incidence of congenital malformations in the study period of 26 months (April 2010 through May 2012) was 1.04\% 11675 deliveries. It is much lower than $2-7 \%$ reported in most studies ${ }^{[11,12]}$. One of the reason for this could be that the study was carried out in a general maternity hospital catering mainly to low risk pregnancies and deliveries.

Detection rates for fetal congenital malformations depend on a multitude of factors like differences in operator skill, equipment used or the gestation at which it was performed. Findings of the Eursoscan study have shown that the rate of detection of anomalies varies between registries for different system anomalies ${ }^{[13]}$. This was a study spread across 20 registries involving 709030 consecutive births that diagnosed 8,126 malformed fetuses/ babies. The detection rate varied for different malformations. It varied from $62 \%$ to $97 \%$ for neural tube defect, $11 \%$ to $48 \%$ for congenital heart diseases, nil to $64 \%$ for limb reduction deficiencies, none to $75 \%$ for cleft lip/ palate, $18 \%$ to $100 \%$ for gastroschisis and $38 \%$ to $72 \%$ for gastrointestinal anomalies ${ }^{[13]}$. In the present study, the overall detection rate for anomalies was $50 \%$ when the ultrasound was done between $14-24$ weeks. The rate of detection for different anomalies by ultrasound was $77.8 \%$ for neural tube defects, $21.4 \%$ for facial defects, $33.3 \%$ for cardiac malformations, $25 \%$ for limb defects and $48.7 \%$ for multiple anomalies. Large variation in detection rates of congenital cardiac abnormalities is known. First trimester scan may be able to detect cardiac anomalies in $44.8 \%$ of cases and near equal numbers could be identified during the anomaly scan around 20 weeks. There will nearly be $7-8 \%$ cases detected in 3 rd trimester or after birth ${ }^{[14]}$. While experienced tertiary centers report a high level of diagnostic accuracy, with most major forms of congenital heart disease being detectable before birth, the overall detection rate remains low. Those centers that report high rates are the ones who receive babies detected to have or such pregnancies who are referred for being at increased risk of having an affected baby. Most cases of congenital heart disease will, however, occur in low risk pregnancies ${ }^{[15]}$.

Although the population was the same, the sonographic units and the screening physicians were different. Of the missed anomalies, 8 were neural tube defects and intracranial anatomical malformations which are known to have a high detection rate by ultrasound. Other anomalies undetected by ultrasound were cleft lip and palate, limb defects, cardiac anomalies, gastroschisis, imperforate anus, cystic hygroma and ambiguous genitalia.

Timely antenatal diagnosis of malformations before 20 weeks of pregnancy will provide an opportunity to confirm, consult, counsel and then to intervene (if required, with termination of pregnancy safely within the legal bounds). In the present study, 16 of 17 cases with the anomaly diagnosed prior to 20 weeks had pregnancy termination. In $72.6 \%$ of the 
cases (26, 16 and 30 per cent by 24,28 and beyond 28 weeks, respectively) who had the anomaly diagnosed after 20 weeks, the chance to offer timely counsel was probably missed as they had an antenatal visit before 20 weeks.

Of 121 women with a fetal anomaly, most (101 cases, 83.5\%) had their first antenatal visit prior to 20 weeks. Less than a third of these with an early trimester visit (32 of 101 cases, $31.7 \%$ ) had FADS done prior to 20 weeks. This number is quite low especially when it has been established that routine ultrasound in early pregnancy leads to earlier detection of clinically unsuspected fetal malformations at a time when termination of pregnancy is possible ${ }^{[16]}$. Seeing that 6 of 10 women $(60 \%)$ who were under care since the diagnosis of pregnancy, having returned their visit before 20 weeks and having the anomaly picked up, it can be argued that proper antenatal counselling does result in a higher rate of compliance and detection of anomalies at the right time. Although the numbers are small, it reiterates the need for appropriate counselling of the couple regarding the need to have the FADS before 20 weeks.

This analysis has brought forth three issues: one, the importance of counselling and necessity of planning the visit for ultrasonographic screening for fetal anomaly at the first trimester antenatal visits. Secondly, the requirement to train the sonologists and provide technical guidelines so that the expertise developed will help minimize missing anomalies. Despite all efforts to hone the skill of physicians at sonography and the increased patient compliance with advice to report for anomaly screening before 20 weeks, there still will be anomalies that would become more pronounced after that period. Anomalies such as congenital diaphragmatic hernia, microcephaly and hydrocephalus may not be evident until the late second trimester ${ }^{[17]}$, much after the time of a standard detailed scan and will therefore be missed at the routine 18-20 weeks. The third issue that draws attention is with regard to the permissible upper limit of gestational age for termination of pregnancy under the MTP Act in India. It may be necessary to raise the upper limit of gestational age beyond 20 weeks or de-link termination of pregnancy for anomalous fetuses from the provisos of the MTP Act. Termination of pregnancy in the situation of a severe fetal malformation should be considered akin to termination for ectopic and molar pregnancies. It is suggested that the opinion of health care practitioners, obstetricians, ethicists, parents and the legal fraternity in this regard needs to be obtained and an agreement generated.

\section{Acknowledgement}

Permission given by Medical Superintendent and Heads of Clinical Units at Government District Lady Goschen Hospital, Mangalore to analyze the case records is thankfully acknowledged.

\section{References}

[1] Kumar V, Abbas K and Fausto N eds, Robbins and Cotran's Pathologic Basis of Disease, 7th edition, W.B. Saunders Company, ISBN: 0721601871 p.470

[2] Garne E, Loane M, Dolk H, De Vigan C, Scarano G, Tucker D, et al. Prenatal diagnosis of severe structural congenital malformations in Europe. Ultrasound Obstet Gynecol. 2005; 25: 6-11 PMid:15619321

[3] Grover N. Congenital Malformations in Shimla. Indian J of Paediatr. 2000; 67: 249-51. PMID: 10878862

[4] Felix EO, Richard OC, Ifeanyi A, Chukwuku UA. Patterns and Prevalence of fetal anomalies in South-South Nigeria: A 2 year retrospective study using ultrasound screening. Eruopean J Radiography. 2009; 1: 155-159. http://dx.doi.org/10.1016/j.ejradi.2010.04.003

[5] FOGSI-ICOG Good Clinical Practice Guidelines. Recommendations for Routine Antenatal Care for Healthy Pregnant Woman 1.7.1 http://www.icogonline.org/images/pdf/gcpguidelines/Care_for_the_Healthy_Pregnant_Women.pdf downloaded on 12 May 2012)

[6] Ballantyne A, Newson A, Luna F, Ashcroft R. Prenatal Diagnosis and Abortion for Congenital Abnormalities: Is it Ethical to Provide One Without the Other. The American Journal of Bioethics. 2009; 9: 48-56 PMid: 19998163 http://dx.doi.org/10.1080/15265160902984996

[7] Legal and ethical aspects of abortion. In: The Care of Women Requesting Induced Abortion Evidence-based Clinical Guideline. 2004; 7(3). RCOG Press. London ISBN 1-904752-06-3 
[8] Jackson E, Johnson BR, Gebreselassie H, Kangaude GD, Mhangoe C. A strategic assessment of unsafe abortion in Malawi. Reprod Health Matters. 2011;19: 133-143 PMID: 21555094 http://dx.doi.org/10.1016/S0968-8080(11)37563-5

[9] Hessini L. Abortion and Islam: Policies and Practice in the Middle East and North Africa. Reprod Health Matters. $2007 ; 15: 75-84$. PMID: 17512379 http://dx.doi.org/10.1016/S0968-8080(06)29279-6

[10] The Medical Termiantion of Pregnancy Act. 1971. (http://www.mp.gov.in/health/acts/mtp\%20Act.pdf; accessed on 08/03/2012)

[11] Karbasi SA, Golestan M, Fallah R, Mirnaseri F, Barkhordari K, Bafghee MS. Prevalence of Congenital Malformations in Yazd (Iran). Acta Medica Iranica. 2009; 47: 149-153.

[12] Sawardekar KP. Profile of major congenital malformations at Nizwa Hospital, Oman: 10-year review. J Paediatr Child Health. 2005; 41: 323-30. PMID: 16014135 http://dx.doi.org/10.1111/j.1440-1754.2005.00625.x

[13] Clementi M, Stoll C. The Euroscan Study. Ultrasound Obstet Gynecol. 2001; 18: 297-300 PMID: 11778985 http://dx.doi.org/10.1046/j.0960-7692.2001.00555.x

[14] Eleftheriades M, Tsapakis E, Sotiriadis A, Manolakos E, Hassiakos D, Botsis D. Detection of congenital heart defects throughout pregnancy; impact of first trimesterultrasound screening for cardiac abnormalities. J Matern Fetal Neonatal Med. 2012 Jul 6. [Epub ahead of print] PMid: 22712625

[15] Sharland G. Fetal cardiac screening and variation in prenatal detection ratesof congenital heart disease: why bother with screening at all? Future Cardiol. 2012; 8: 189-202 PMID: 22413979

[16] Neilson JP. Ultrasound for fetal assessment in early pregnancy. Cochrane Database of Systematic Reviews 1998, Issue 4. Art. No.:CD000182. PMid:10796174 http//dx.doi.prg/10.1002/14651858.CD000182

[17] Chitty LS, Hunt GH, Moore J, Lobb MO. Effectiveness of routine ultrasonography in detecting fetal structural problems in a low risk population. BMJ 1991; 303: 1165-9. PMID: 1747613 http://dx.doi.org/10.1136/bmj.303.6811.1165

[18] Allan L. Antenatal diagnosis of heart disease. Heart. 2000; 83: 367-368 PMid: 10677423 